\title{
A predictive nomogram: a cross-sectional study on a simple-to-use model for screening 12-year-old children for severe caries in middle schools
}

\author{
Shaoying Duan ${ }^{1 \dagger}$, Meng $\mathrm{Li}^{2+}$, Jialiang Zhao ${ }^{1}$, Huiyu Yang ${ }^{1}$, Jinfeng He${ }^{1}$, Lei Lei ${ }^{1}$, Ran Cheng ${ }^{1 *}$ and Tao Hu ${ }^{1 *}$
}

\begin{abstract}
Background: A nomogram is a tool that transforms complex regression equations into simple and visual graphs and enables clinicians and patients to conveniently compute output probabilities without needing medical knowledge and complex formulas. The aim of this study was to develop and validate a predictive nomogram to screen for severe caries among 12-year-old children based on risk factors in Sichuan Province, China.

Methods: A cross-sectional study of 4573 12-year-olds was conducted up to May 2016 in middle schools from three districts and three counties in Sichuan Province, China. All the children underwent oral examinations and completed questionnaires to assess general information, oral impacts on daily performance, dietary habits, subjective health conditions, history of dental trauma, frequency of toothache, dental visits, and knowledge, attitudes, and behaviours toward oral hygiene. Univariate analysis and multivariate logistic regression analysis were used to determine which variables were significantly associated with severe caries (operationalized as DMFT $\geq 3$ ). A nomogram was developed and validated by using the 'rms' package and two cross-validation methods.
\end{abstract}

Results: Severe caries was found in 537 of the 4573 children (11.74\%). Multivariate logistic regression analysis revealed that the following variables predicted a higher risk of severe caries: 'female' [odds ratio $(O R)=1.985,95 \%$ confidence interval (95\% Cl): 1.63-2.411], 'urban' (OR=2.389, 95\% Cl: 1.96-2.91),'non-only child' $(\mathrm{OR}=1.317,95 \% \mathrm{Cl}$ : 1.07-1.625), 'very poor self-assessment of oral health status' $(\mathrm{OR}=2.157,95 \% \mathrm{Cl}: 1.34-3.467)$ and 'visited a dentist less than 6 months' $(\mathrm{OR}=1.861,95 \% \mathrm{Cl}: 1.38-2.505)$. Multivariate logistic regression analysis also indicated that the following variables predicted a lower risk of severe caries: 'middle level of urbanization' (OR $=0.395,95 \% \mathrm{Cl}$ : 0.32-0.495) and 'high level of urbanization' ( $\mathrm{OR}=0.466,95 \% \mathrm{Cl}: 0.37-0.596)$. Both the fivefold and leave-one-out cross-validation methods indicated that the nomogram model built by these 6 variables displayed good disease recognition ability.

Conclusions: The nomogram was a simple-to-use model to screen children for severe caries. This model was found to facilitate non-dental professionals in assessing risk values without oral examinations and making referrals to dental professionals.

\footnotetext{
*Correspondence: chengran@scu.edu.cn; hutao@scu.edu.cn

†Shaoying Duan and Meng Li contributed equally to this work

${ }^{1}$ Department of Preventive Dentistry, State Key Laboratory of Oral

Diseases, National Clinical Research Center for Oral Diseases, West China

Hospital of Stomatology, Sichuan University, Chengdu, Sichuan, China

Full list of author information is available at the end of the article
}

(c) The Author(s) 2021. Open Access This article is licensed under a Creative Commons Attribution 4.0 International License, which permits use, sharing, adaptation, distribution and reproduction in any medium or format, as long as you give appropriate credit to the original author(s) and the source, provide a link to the Creative Commons licence, and indicate if changes were made. The images or other third party material in this article are included in the article's Creative Commons licence, unless indicated otherwise in a credit line to the material. If material is not included in the article's Creative Commons licence and your intended use is not permitted by statutory regulation or exceeds the permitted use, you will need to obtain permission directly from the copyright holder. To view a copy of this licence, visit http://creativecommons.org/licenses/by/4.0/. The Creative Commons Public Domain Dedication waiver (http://creativecommons.org/publicdomain/zero/1.0/) applies to the data made available in this article, unless otherwise stated in a credit line to the data. 
Keywords: Epidemiology, Caries risk, Oral health, Regression analysis, Models, Statistical, Cross-sectional studies

\section{Background}

Dental caries is one of the most prevalent chronic diseases; it occurs among susceptible children who are at risk for developing decay and progresses throughout their life spans $[1,2]$. Dental caries also diminishes oral health-related quality of life [3]. The global oral health goal was that by the year 2000, the mean decayed, missing, and filled teeth (DMFT) index among 12-year-old children would be no more than 3 , which was accepted for caries prevention by the World Health Organization (WHO) and the International Dental Federation (FDI) in 1981 [4,5]. Although China has maintained a mean DMFT of $\leq 1.00$ since 1983 owing to the use of fluoride and the achievement of oral health education [6], the distribution of caries remains skewed. It has been reported that most cases of caries are found in only a small number of children [7, 8]. Thus, we can obtain the Significant Caries $(\mathrm{SiC})$ Index of a certain area by examining one-third of the local children who have the highest number of DMFT. According to the global goal of caries levels that was proposed in 2000, the $\mathrm{SiC}$ index should have been less than 3 DMFT among 12-year-old children by 2015 [9]. Screening out children with severe caries and taking targeted preventive measures will help save socioeconomic resources, improve cariesrelated outcomes and contribute to better oral health.

Data from the World Health Survey showed that oral healthcare coverage was $46.5 \%$ in China [10]. Located in southwestern China, Sichuan Province had a population of 83.41 million in 2018, but there were only 9,225 dental practitioners and assistants [11]. Moreover, Chinese parents rarely take their children to regular oral examinations. Therefore, a simple-to-use predictive model is required to help non-dental professionals (e.g., medical staff at community facilities or school doctors) assess risk values without oral examinations and make referrals to dental professionals.

Nomograms are widely used as reliable risk prediction tools [12-14] and can generate a numeral probability by integrating risk variables. This model is simple and rapid for application because it does not require complex mathematical formulas or medical knowledge. Although there have been studies on nomograms in the dental field [15], to the best of our knowledge, few studies have formulated nomograms suitable for screening for severe caries.

This article aimed to investigate risk factors for severe caries in children and to develop and validate a simpleto-use nomogram to screen for severe caries among 12-year-old children based on the risk level calculated in Sichuan Province, China.

\section{Methods}

A cross-sectional survey of children aged 12 years was conducted in Sichuan Province between December 2015 and May 2016. Ethics approval of the Oral Health Survey was obtained from the Stomatological Ethics Committee of the Chinese Stomatological Association and the Ethics Committee of the West China Hospital of Stomatology, Sichuan University (Approval No. 2014-003). Consent for participation and publication was also obtained from the parents or legal guardians of the children in this study.

\section{Sampling}

A multistage stratified random-cluster survey sampling design was used for participant selection [16]. In the first stage, based on the 2010 census conducted by the National Bureau of Statistics of the People's Republic of China, three districts and three counties in Sichuan Province (Guang'an, Chuanshan, and Jinniu Districts, Yibin, $\mathrm{Da}$, and Pi Counties) were randomly selected to represent low/middle/high levels of urbanization by probability-proportional-to-size (PPS) [17]. Next, a simple random sampling method was used to select middle schools. Consisting of 3 private schools and 28 public schools, a total number of 31 randomly-selected schools got involved in the study. Finally, all 12-year-old children from the selected schools in each area were invited to participate in the study. The ages were calculated according to the survey month. The sample size was calculated based on the following formula:

$$
n=\operatorname{deff} \frac{\mu^{2}(1-p)}{\varepsilon^{2} p(1-\text { nonresponse })},
$$

where $\mathrm{n}$ is the sample size, the design effect deff is $2.5, p$ is $28.9 \%$ according to the dental caries prevalence in the Third National Oral Health Survey, $\mu$ (1.96) is the level of confidence, $\varepsilon(7.5 \%)$ is the margin of error, and the nonresponse rate is $5 \%$ [18]. The formula above indicated that a sample size of 4420 12-year-old children was required.

\section{Quality control}

To ensure inter-examiner reliability, 4 trained and licensed dentists, including three training examiners and one calibrating examiner, were required to receive the pre-survey calibration training. The results of caries examination for schoolchildren were recorded by assistants. To ensure intra-examiner reliability of oral 
examination, $5 \%$ of samples were selected for duplicate examination, then compared with the original data and with the calibrating examiner every day during the survey. Cohen's kappa statistics assessing the consistency of inter- and intra-examiner were all exceeded 0.80 [19].

\section{Caries examination}

After parents signed informed consent forms, all 4800 schoolchildren who participated in questionnaire surveys were examined on mobile dental chairs with portable lights at the schools. A tooth was classified as decayed when there was a lesion in a pit or fissure; on a smooth tooth surface with an unmistakable cavity; on undermined enamel; or on a detectably softened floor or wall. The DMFT of permanent teeth examinations mainly relied on ocular inspection with the help of Community Periodontal Index (CPI) probes as recommended by the WHO for clinical examinations [20]. This DMFT index covers the teeth and/or tooth number that were decayed, filled or extracted as a result of caries, which we used to assess dental caries.

\section{Questionnaire}

Thirty-nine closed questions (see Additional file 1) were designed by experts based on the variables suggested by the WHO [20]. Paper printed questionnaires were completed by children individually in the classroom under the explanations of one licenced dentist. If a child did not fill the questionnaires completely or did not qualify, they were excluded from the analyses.

\section{Independent variables}

Thirty-nine independent variables came from questionnaire containing children's socio-demographic information, including age, gender, districts/counties (Guang'an, Chuanshan, and Jinniu Districts, Yibin, Da, and Pi Counties) represent different level of urbanization, region (urban/rural), father/mother's education level (illiterate/ low/medium/high), only child (yes/no) and oral impacts on daily performances (serious/general/slight/none/ does not know; impact on eating, talking, brushing, working, schooling, sleeping, grinning, communicating, and if easily troubled). Additionally, questions assessing dietary habits, subjective health conditions, history of dental trauma, frequency of toothache in the previous 12 months, dental visits, and knowledge, attitudes, and behaviours toward oral hygiene were also included.

\section{Outcome variable selection}

The global goal for dental caries prevention among 12-year-olds was an $\mathrm{SiC}$ Index less than 3 DMFT [9]. Therefore, the outcome variable in this study was set as a binary variable based on whether a child had severe caries (DMFT $\geq 3$ ).

\section{Statistical analysis}

Statistical analyses were performed using SAS 9.4 (SAS Institute, Inc., Cary, NC) for Windows. Univariate analyses (chi-squared tests) were first conducted to locate factors that might be associated with the outcome variable. Second, a multivariate logistic regression model was built to evaluate the association of the outcome variables with the selected variables mentioned above using a backward selection method (entry significance level $=0.05$, stay significance level $=0.10)[21,22]$. The partial regression coefficient $(\beta)$, Wald's $\chi^{2}, P$-value (Wald test), odds ratio (OR) and $95 \%$ confidence intervals $(95 \% \mathrm{CI}$ ) were estimated to specify the predictive model. Third, a nomogram was constructed based on the results of a multivariate logistic regression model by using the 'rms' package in $\mathrm{R}$ version 2.14.1 (http://www.r-project.org/). Finally, the prediction performance of the model was assessed by using both fivefold and leave-one-out crossvalidation $(\mathrm{CV})$ methods. The fivefold $\mathrm{CV}$ method was conducted according to the following steps: (i) data were randomly divided into five parts; (ii) one-fifth of the data was set aside as a validation dataset, and a logistic regression model was fitted using the remaining four-fifths (the training dataset); (iii) the resulting training model was used to calculate the predicted probability of each validation observation; (iv) steps (i) to (iii) were repeated four more times; and (v) average indicators were calculated. Indicators, including sensitivity, specificity, falsepositive rate (FPR), false-negative rate (FNR), negative predictive value (NPV), positive predictive value (PPV), Youden Index (YI), accuracy, and area under the curve (AUC), were calculated for training, validation, and all data to assess the predictive ability of the model. For a similar reason, the leave-one-out $\mathrm{CV}$ method was used to fit the model for all cases except one and then tested on the set-aside case. This process was repeated for each observation in the original sample (random sampling without replacement). A receiver operating characteristic (ROC) curve and a calibration curve were also generated to assess the predictive ability of the model. All statistical tests (except stay significance level of multivariate logistic regression model) were two-tailed with the significance levels set to 0.05 .

\section{Results}

\section{Socio-demographic characteristics}

A total of 4800 children participated in the survey. Among them, 227 children were excluded due to failure to complete questionnaires. Ultimately, 4573 children were included in this study, and the response rate was 
94.27\%. DMFT index and its components were presented in Table 1. Among the 4573 12-year-olds, 2248 (49.16\%) had experience with caries (DMFT $\geq 1$ ), including 1048 boys and 1200 girls. Only 537 (11.74\%) children had severe caries (DMFT $\geq 3$ ), which revealed a significantly skewed distribution.

\section{Univariate analysis}

Univariate analyses (chi-squared tests) were conducted first, and 16 factors were found to be statistically significantly associated with DMFT $\geq 3(P<0.05$; Table 2$)$ : socio-demographic information ('gender', 'region', 'only child', 'urbanization'), cariogenic diet ('candy/chocolate/ cookies/cakes'), self-assessment ('self-assessment of oral health status'), trauma ('history of dental trauma'), toothache ('frequency of toothache in the previous 12 months'), dental visit ('history of dental visits', 'reason for last dental visit,' 'time of last dental visit'), oral hygiene knowledge and attitude ('fluoride can protect teeth', 'pit and fissure sealing can protect teeth', 'regular dental check is necessary'), and oral impacts on daily performances ('impact on sleeping', 'impact on grinning').

\section{Multivariate logistic regression}

A multivariate logistic regression model was built with the selected variables. For the predictive model, the following variables were included: 'female', 'urban', 'low level of urbanization,' 'only child', 'poor or very poor oral health for self-assessment', and 'visited a dentist less than 6 months or more than 12 months ago' $(P<0.1$; Table 3$)$.

\section{Nomogram formulation}

A simple-to-use nomogram was formulated based on six risk factors for the children with severe caries by multivariate logistic regression (Fig. 1). The longer the variable scales were, the more relative importance they had. 'Risk' indicated the possibility of a child with severe caries (DMFT $\geq 3$ ), and the cut-off point was 0.1332 based on the ROC curve.

\section{Model validation}

We assessed the discrimination performance of the model using fivefold $\mathrm{CV}$ and leave-one-out $\mathrm{CV}$ methods, providing five ROC curves with both validation data and training data (Fig. 2). The mean areas under the ROC curve (AUCs) were 0.6848 (95\% CI: 0.6157, 0.7539)

Table 1 Dental caries status of 12-year-old children in Sichuan province, 2015-2016

\begin{tabular}{|c|c|c|c|c|c|c|c|c|}
\hline \multirow[t]{2}{*}{ Variable } & \multirow[t]{2}{*}{ n (\%) } & \multirow{2}{*}{$\begin{array}{l}\text { DMFT } \\
\text { Mean (SD) }\end{array}$} & \multicolumn{2}{|l|}{ D } & \multicolumn{2}{|l|}{$M$} & \multicolumn{2}{|l|}{$\mathbf{F}$} \\
\hline & & & Mean (SD) & Rate (\%) & Mean (SD) & Rate (\%) & Mean (SD) & Rate (\%) \\
\hline \multicolumn{9}{|l|}{ Gender } \\
\hline Male & $2227(48.7)$ & $0.64(1.29)$ & $0.59(1.22)$ & 29.23 & $0.00(0.02)$ & 0.04 & $0.05(0.34)$ & 3.05 \\
\hline Female & 2346 (51.3) & 1.07 (1.73) & $0.95(1.62)$ & 40.41 & $0.00(0.05)$ & 0.09 & $0.11(0.54)$ & 5.80 \\
\hline \multicolumn{9}{|l|}{ Region } \\
\hline Urban & $2275(49.7)$ & $1.05(1.68)$ & $0.98(1.63)$ & 41.30 & $0.00(0.02)$ & 0.04 & $0.07(0.39)$ & 3.57 \\
\hline Rural & $2298(50.3)$ & $0.67(1.36)$ & $0.57(1.21)$ & 28.57 & $0.00(0.05)$ & 0.09 & $0.10(0.51)$ & 5.36 \\
\hline \multicolumn{9}{|c|}{ Urbanization } \\
\hline Low & $1614(35.3)$ & $1.13(1.77)$ & $1.10(1.73)$ & 43.68 & $0.00(0.03)$ & 0.06 & $0.04(0.29)$ & 1.98 \\
\hline Middle & 1680 (36.7) & $0.68(1.37)$ & $0.60(1.26)$ & 30.00 & $0.00(0.02)$ & 0.06 & $0.07(0.45)$ & 4.05 \\
\hline High & 1279 (28.0) & $0.75(1.40)$ & $0.59(1.12)$ & 30.49 & $0.00(0.06)$ & 0.08 & $0.15(0.60)$ & 8.13 \\
\hline \multicolumn{9}{|c|}{ Mother's education level } \\
\hline Illiterate & $832(18.2)$ & $0.88(1.64)$ & $0.80(1.56)$ & 34.98 & $0.00(0.03)$ & 0.12 & $0.08(0.43)$ & 4.57 \\
\hline Low & 905 (19.8) & $0.82(1.44)$ & $0.76(1.37)$ & 35.03 & $0.00(0.03)$ & 0.11 & $0.06(0.34)$ & 3.31 \\
\hline Medium & 1677 (36.7) & $0.89(1.57)$ & $0.82(1.50)$ & 36.85 & $0.00(0.00)$ & 0.00 & $0.07(0.42)$ & 3.58 \\
\hline High & 1159 (25.3) & $0.83(1.50)$ & $0.70(1.35)$ & 32.18 & $0.00(0.06)$ & 0.09 & $0.13(0.58)$ & 6.56 \\
\hline \multicolumn{9}{|c|}{ Father's education level } \\
\hline Illiterate & 775 (16.9) & $0.89(1.61)$ & $0.80(1.51)$ & 36.00 & $0.00(0.05)$ & 0.26 & $0.09(0.45)$ & 5.03 \\
\hline Low & $678(14.8)$ & $0.72(1.32)$ & $0.67(1.24)$ & 34.07 & $0.00(0.08)$ & 0.15 & $0.05(0.36)$ & 2.36 \\
\hline Medium & $1704(37.3)$ & $0.89(1.62)$ & $0.84(1.56)$ & 36.09 & $0.00(0.00)$ & 0.00 & $0.05(0.35)$ & 3.11 \\
\hline High & $1416(31.0)$ & $0.86(1.51)$ & $0.73(1.37)$ & 33.47 & $0.00(0.00)$ & 0.00 & $0.13(0.59)$ & 6.78 \\
\hline \multicolumn{9}{|l|}{ Only child } \\
\hline Yes & $1665(36.4)$ & $0.75(1.43)$ & $0.62(1.26)$ & 31.05 & $0.00(0.05)$ & 0.06 & $0.13(0.59)$ & 6.37 \\
\hline No & 2908 (63.6) & $0.92(1.60)$ & $0.86(1.54)$ & 37.21 & $0.00(0.03)$ & 0.07 & $0.06(0.35)$ & 3.37 \\
\hline Total & $4573(100.0)$ & $0.86(1.54)$ & $0.77(1.45)$ & 34.97 & $0.00(0.00)$ & 0.07 & $0.08(0.45)$ & 4.46 \\
\hline
\end{tabular}


Table 2 Description of the potential risk indicators selected by univariate analysis

\begin{tabular}{|c|c|c|c|c|}
\hline Variables & DMFT $\geq 3(\%)$ & DMFT <3 (\%) & $x^{2}$ & $P$ \\
\hline \multicolumn{5}{|l|}{ Gender } \\
\hline Male & $183(8.22)$ & 2044 (91.78) & \multirow[t]{2}{*}{52.0611} & \multirow[t]{2}{*}{$<0.0001^{* * *}$} \\
\hline Female & 354 (15.09) & $1992(84.91)$ & & \\
\hline \multicolumn{5}{|l|}{ Region } \\
\hline Urban & $361(15.87)$ & $1914(84.13)$ & \multirow[t]{2}{*}{74.0525} & \multirow[t]{2}{*}{$<0.0001^{* * *}$} \\
\hline Rural & $176(7.66)$ & $2122(92.34)$ & & \\
\hline \multicolumn{5}{|l|}{ Urbanization } \\
\hline Low & $280(17.35)$ & $1334(82.65)$ & \multirow[t]{3}{*}{77.6834} & \multirow[t]{3}{*}{$<0.0001^{* * *}$} \\
\hline Middle & $134(7.98)$ & $1546(92.02)$ & & \\
\hline High & $123(9.61)$ & $1156(90.38)$ & & \\
\hline \multicolumn{5}{|c|}{ Candy/chocolate/cookies/cakes } \\
\hline Never/seldom & $46(8.80)$ & $477(91.20)$ & \multirow[t]{6}{*}{14.3734} & \multirow[t]{6}{*}{$0.0134^{* *}$} \\
\hline $\begin{array}{l}\text { 1-3 times/ } \\
\text { month }\end{array}$ & $57(9.61)$ & $536(90.39)$ & & \\
\hline Once/week & 75 (10.55) & $636(89.45)$ & & \\
\hline 2-6 times/week & $167(12.46)$ & $1173(87.54)$ & & \\
\hline Once/day & $107(13.02)$ & $715(86.98)$ & & \\
\hline$\geq 2$ times/day & $85(14.55)$ & $499(85.45)$ & & \\
\hline \multicolumn{5}{|l|}{ Only child } \\
\hline Yes & $161(9.67)$ & $1504(90.33)$ & \multirow[t]{2}{*}{10.8584} & \multirow[t]{2}{*}{$0.0010^{* *}$} \\
\hline No & $376(12.93)$ & $2532(87.07)$ & & \\
\hline \multicolumn{5}{|c|}{ Self-assessment of oral health status } \\
\hline Very good & $8(6.25)$ & $120(93.75)$ & \multirow[t]{5}{*}{30.5292} & \multirow[t]{5}{*}{$<0.0001^{* * *}$} \\
\hline Good & $98(9.82)$ & $900(90.18)$ & & \\
\hline Average & $288(11.14)$ & $2298(88.86)$ & & \\
\hline Poor & $117(15.88)$ & $620(84.12)$ & & \\
\hline Very poor & $26(20.97)$ & $98(79.03)$ & & \\
\hline \multicolumn{5}{|c|}{ History of dental trauma } \\
\hline Yes & $141(11.80)$ & $1054(88.20)$ & \multirow[t]{3}{*}{6.0979} & \multirow[t]{3}{*}{$0.0474^{*}$} \\
\hline No & $212(10.59)$ & $1790(89.41)$ & & \\
\hline Don't remember & $184(13.37)$ & $1192(86.63)$ & & \\
\hline \multicolumn{5}{|c|}{ Frequency of toothache in the previous 12 months } \\
\hline Often & $20(18.18)$ & $90(81.82)$ & \multirow[t]{4}{*}{11.6055} & $0.0089^{* *}$ \\
\hline Occasionally & $320(12.50)$ & $2241(87.50)$ & & \\
\hline Never & $129(9.63)$ & $1210(90.37)$ & & \\
\hline Don't remember & $68(12.08)$ & $495(87.92)$ & & \\
\hline History of dental vi & & & & \\
\hline Yes & $286(13.41)$ & 1847 (86.59) & 10.6997 & $0.0011^{* *}$ \\
\hline No & $251(10.29)$ & $2189(89.71)$ & & \\
\hline Time of last dental & visit & & & \\
\hline Never & $251(10.29)$ & 2191 (89.71) & 16.8472 & $0.0008^{* * *}$ \\
\hline$<6$ months ago & 76 (16.70) & $379(83.30)$ & & \\
\hline $\begin{array}{l}6-12 \text { months } \\
\text { ago }\end{array}$ & 65 (12.17) & 469 (87.83) & & \\
\hline $\begin{array}{l}>12 \text { months } \\
\text { ago }\end{array}$ & 145 (12.68) & 999 (87.33) & & \\
\hline Reason for last der & tal visit & & & \\
\hline $\begin{array}{l}\text { Never/don't } \\
\text { know }\end{array}$ & $408(11.15)$ & 3251 (88.85) & 15.2422 & $0.0016 * *$ \\
\hline Consultation & 34 (12.98) & $228(87.02)$ & & \\
\hline
\end{tabular}

Table 2 (continued)

\begin{tabular}{|c|c|c|c|c|}
\hline Variables & $\mathrm{DMFT} \geq 3(\%)$ & DMFT < $3(\%)$ & $x^{2}$ & $P$ \\
\hline Prevention & $6(5.94)$ & $95(94.06)$ & & \\
\hline Treatment & $89(16.15)$ & $462(83.85)$ & & \\
\hline \multicolumn{5}{|c|}{ Fluoride can protect teeth } \\
\hline Correct & $371(11.15)$ & $2957(88.85)$ & 4.1757 & $0.0410^{*}$ \\
\hline $\begin{array}{l}\text { Wrong/don't } \\
\text { know }\end{array}$ & $166(13.33)$ & $1079(86.67)$ & & \\
\hline \multicolumn{5}{|c|}{ Pit and fissure sealing can protect teeth } \\
\hline Correct & $460(11.39)$ & $3578(88.61)$ & 4.1044 & $0.0428^{*}$ \\
\hline $\begin{array}{l}\text { Wrong/don't } \\
\text { know }\end{array}$ & $77(14.39)$ & $458(85.61)$ & & \\
\hline \multicolumn{5}{|c|}{ Regular dental check is necessary } \\
\hline Agree & $381(12.25)$ & $2730(87.75)$ & 7.8628 & $0.0489^{*}$ \\
\hline Disagree & $8(6.67)$ & $112(93.33)$ & & \\
\hline Perhaps & $81(9.75)$ & $750(90.25)$ & & \\
\hline Don't know & $67(13.11)$ & $444(86.89)$ & & \\
\hline \multicolumn{5}{|c|}{ Impact on sleeping } \\
\hline Serious & $18(14.75)$ & $104(85.25)$ & 21.6344 & $0.0002^{* * *}$ \\
\hline General & $45(17.72)$ & $209(82.28)$ & & \\
\hline Slight & $100(13.81)$ & $624(86.19)$ & & \\
\hline None & $357(11.15)$ & $2846(88.85)$ & & \\
\hline Don't know & $17(6.30)$ & $253(93.70)$ & & \\
\hline \multicolumn{5}{|c|}{ Impact on grinning } \\
\hline Serious & $38(13.67)$ & $240(86.33)$ & 11.9381 & $0.0178^{*}$ \\
\hline General & $60(11.28)$ & $472(88.72)$ & & \\
\hline Slight & $142(13.63)$ & $900(86.37)$ & & \\
\hline None & $278(11.41)$ & 2159 (88.59) & & \\
\hline Don't know & 19 (6.69) & 265 (93.31) & & \\
\hline
\end{tabular}

${ }^{*} P<0.05$, ** $P<0.01$, *** $P<0.001$

for the training data and 0.7053 (95\% CI: 0.6898, 0.7208) for the validation data with fivefold $\mathrm{CV}$. The AUCs were 0.7023 (95\% CI: 0.67682, 0.72778) (Table 4) for all data and 0.6951 for leave-one-out CV (Fig. 2). Additionally, a calibration curve was made to assess the predictive performance of the nomogram (Fig. 3). Sensitivity, specificity, YI, accuracy, FPR, FNR, NPV and PPV were also calculated (Table 4).

\section{Discussion}

The global prevalence and severity of caries are different between developing and developed countries [23, 24], but the first challenge we face is the same: screening out people with severe caries and taking targeted preventive measures [25]. Many caries risk assessment (CRA) tools have been built in previous research on risk factor management, including high-cost examinations such as salivary flow and composition, cariogenic bacteria, and genetic factors [26]. Although these methods improve the accuracy of the predictive model, they require more waiting time, qualified dentists, laboratory technicians, 
Table 3 Selected variables associated with the risk of DMFT $\geq 3$ in the final regression model

\begin{tabular}{|c|c|c|c|c|c|c|}
\hline \multirow[t]{2}{*}{ Independent variables } & \multirow[t]{2}{*}{$\beta$} & \multirow[t]{2}{*}{ Wald $x^{2}$} & \multirow[t]{2}{*}{$P$} & \multirow[t]{2}{*}{ OR } & \multicolumn{2}{|l|}{$95 \% \mathrm{Cl}$} \\
\hline & & & & & Lower & Upper \\
\hline Intercept & -3.8054 & 189.997 & $<0.0001^{* * *}$ & - & - & - \\
\hline \multicolumn{7}{|l|}{ Region (vs. Rural) } \\
\hline Urban & 0.871 & 74.8896 & $<0.0001^{* * *}$ & 2.389 & 1.96 & 2.91 \\
\hline \multicolumn{7}{|l|}{ Urbanization (vs. Low) } \\
\hline Middle & -0.9299 & 65.1115 & $<0.0001^{* * *}$ & 0.395 & 0.32 & 0.495 \\
\hline High & -0.7631 & 36.9668 & $<0.0001^{* * *}$ & 0.466 & 0.37 & 0.596 \\
\hline \multicolumn{7}{|l|}{ Gender (vs. Male) } \\
\hline Female & 0.6854 & 47.5841 & $<0.0001^{* * *}$ & 1.985 & 1.63 & 2.411 \\
\hline \multicolumn{7}{|l|}{ Only child (vs. Yes) } \\
\hline No & 0.2752 & 6.5702 & $0.0104^{*}$ & 1.317 & 1.07 & 1.625 \\
\hline \multicolumn{7}{|c|}{ Self-assessment of oral health status (vs. Average) } \\
\hline Very good & -0.657 & 3.0272 & 0.0819 & 0.518 & 0.25 & 1.087 \\
\hline Good & -0.1532 & 1.427 & 0.2322 & 0.858 & 0.67 & 1.103 \\
\hline Poor & 0.4256 & 11.8617 & $0.0006^{* * *}$ & 1.53 & 1.2 & 1.95 \\
\hline Very poor & 0.7687 & 10.0731 & $0.0015^{* *}$ & 2.157 & 1.34 & 3.467 \\
\hline \multicolumn{7}{|c|}{ Time of last dental visit (vs. Never) } \\
\hline$<6$ months ago & 0.6213 & 16.8055 & $<0.0001^{* * *}$ & 1.861 & 1.38 & 2.505 \\
\hline $6-12$ months ago & 0.1848 & 1.4227 & 0.233 & 1.203 & 0.89 & 1.63 \\
\hline$>12$ months ago & 0.3287 & 7.7635 & $0.0053^{* *}$ & 1.389 & 1.1 & 1.75 \\
\hline
\end{tabular}

${ }^{*} P<0.05$, ** $P<0.01$, *** $P<0.001$

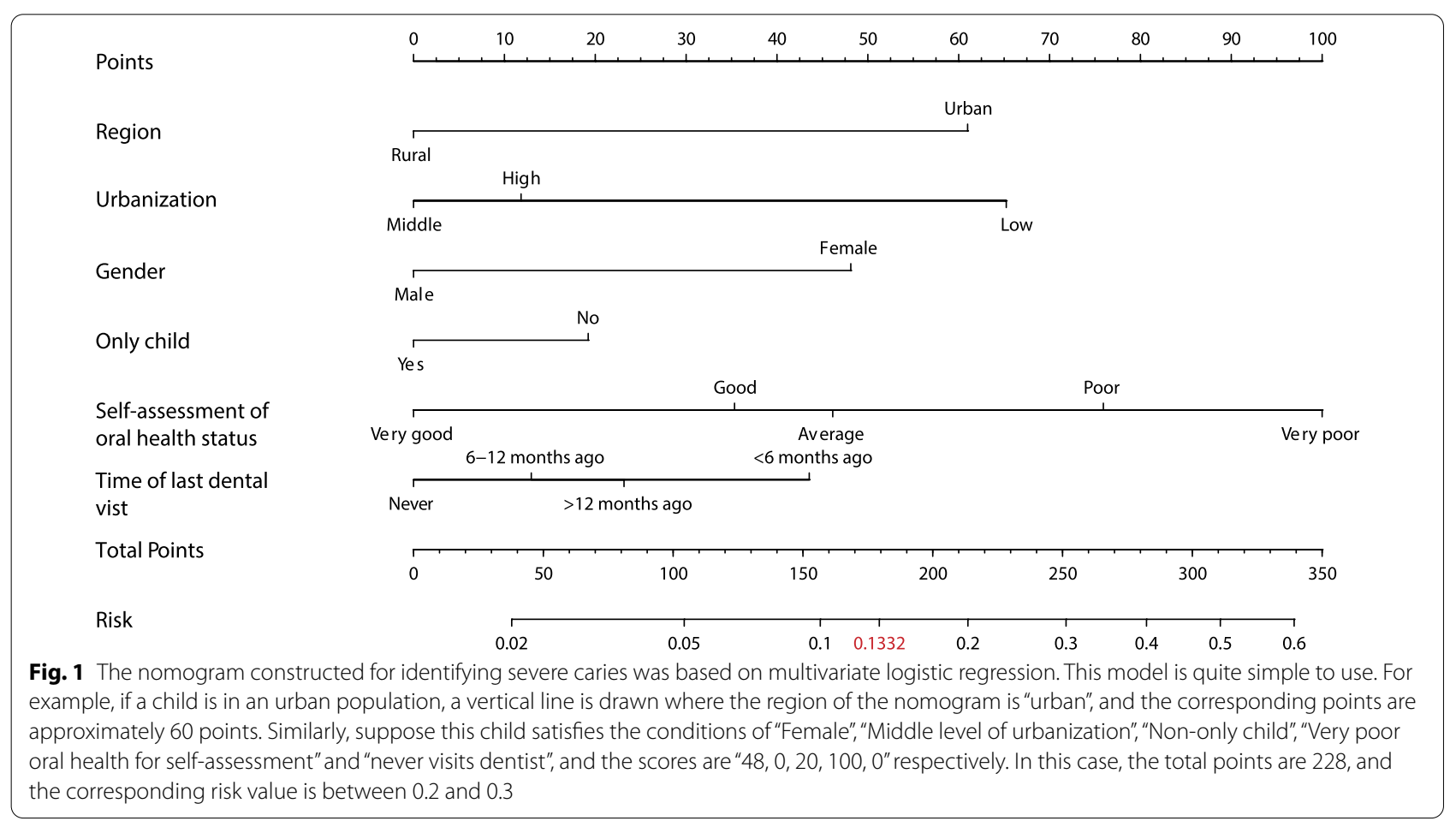




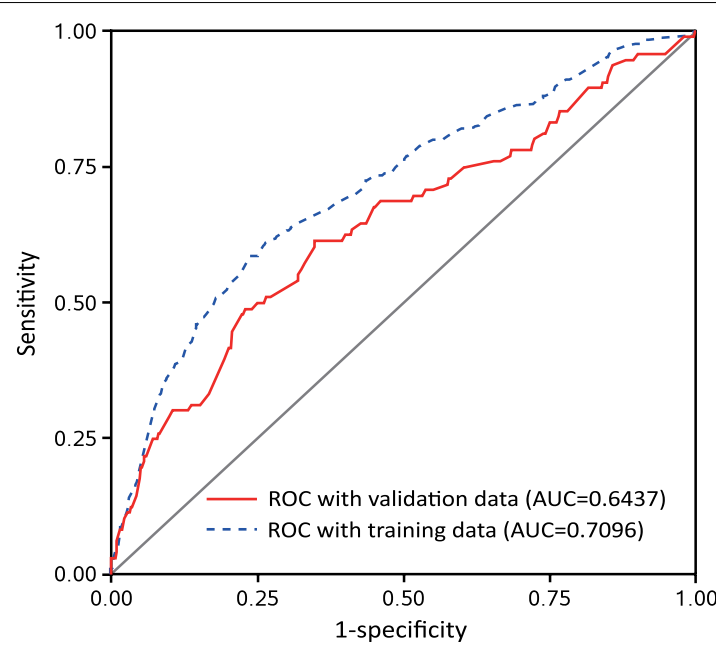

a. ROC with 5-fold CV (step 1).

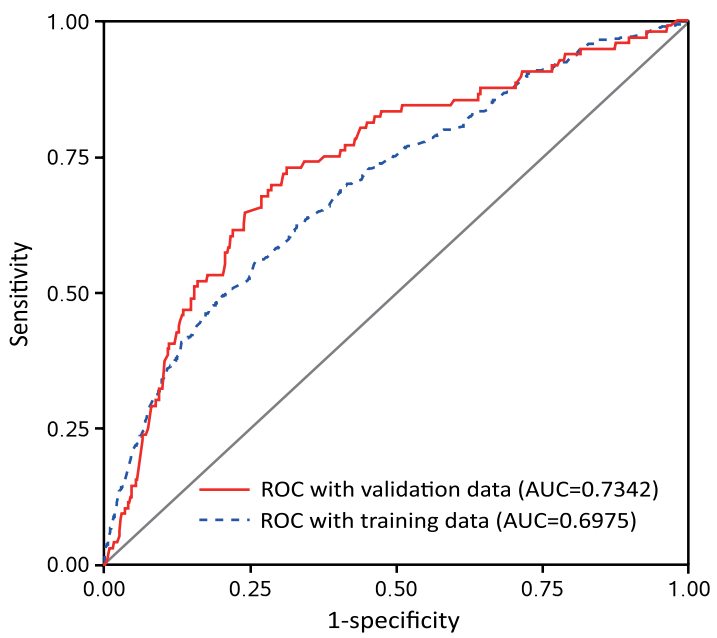

c. ROC with 5-fold CV (step 3).

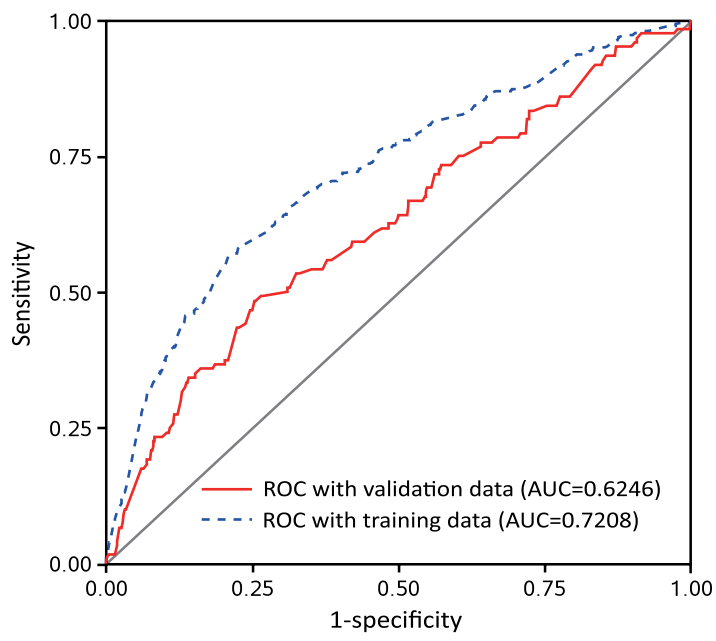

e. ROC with 5-fold CV (step 5).

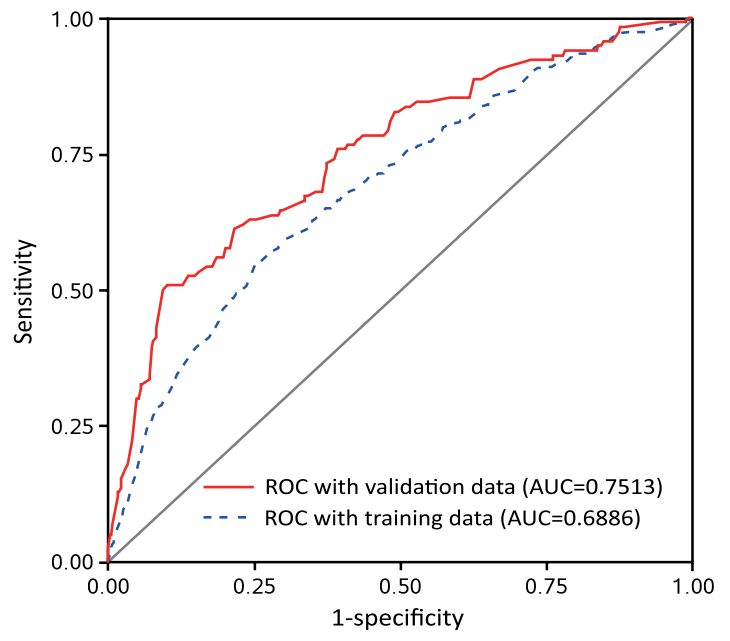

b. ROC with 5-fold CV (step 2).

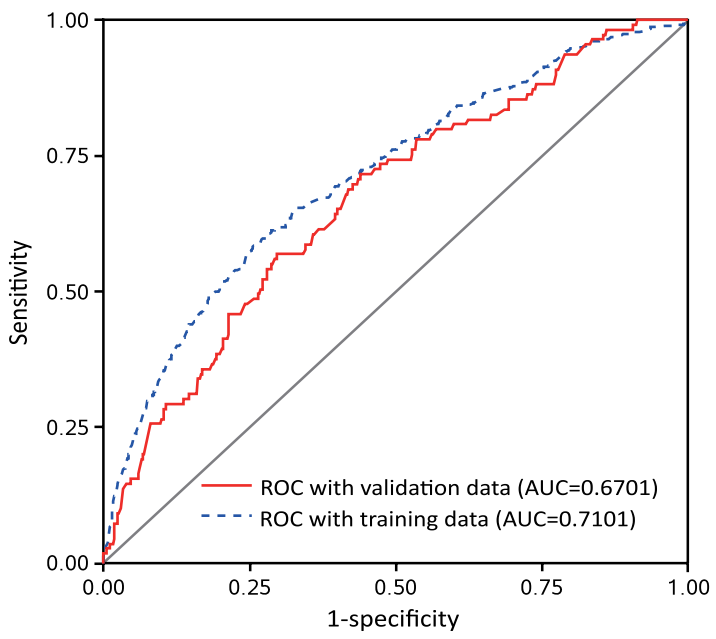

d. ROC with 5-fold CV (step 4).

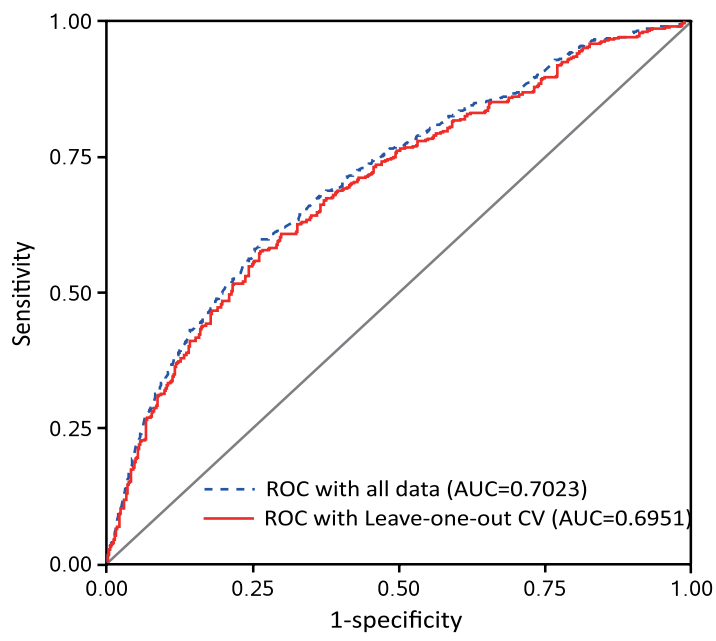

f. ROC with Leave-one-out CV and all data.

Fig. 2 Nomogram ROC curves with fivefold CV and leave-one-out CV. Five ROC curves (a-e) with validation data (red solid line) and training data (blue dashed line) and one ROC curve (f) with leave-one-out CV (red solid line) and all data (blue dashed line) 
Table 4 Validation and evaluation indicators of the screening model in training and validation data

\begin{tabular}{lll}
\hline Indicators & Training data & Validation data \\
\hline Sensitivity & $66.45(64.33,68.57)$ & $66.03(64.30,67.77)$ \\
Specificity & $64.26(59.61,68.91)$ & $63.88(61.56,66.20)$ \\
False positive rate (FPR) & $35.74(31.09,40.39)$ & $36.12(33.80,38.44)$ \\
False negative rate (FNR) & $33.55(31.43,35.67)$ & $33.97(32.23,35.70)$ \\
Positive predictive value (PPV) & $19.90(18.43,21.38)$ & $19.57(18.94,20.20)$ \\
Negative predictive value & $93.50(93.16,93.85)$ & $93.40((93.26,93.54)$ \\
(NPV) & & \\
Youden Index (YI) & $30.71(27.36,34.06)$ & $29.91(28.96,30.86)$ \\
Accuracy (ACC) & $64.53(60.61,68.44)$ & $64.13(62.27,65.99)$ \\
Area under curve (AUC) & $70.53(68.98,72.08)$ & $68.48(61.57,75.39)$ \\
\hline
\end{tabular}

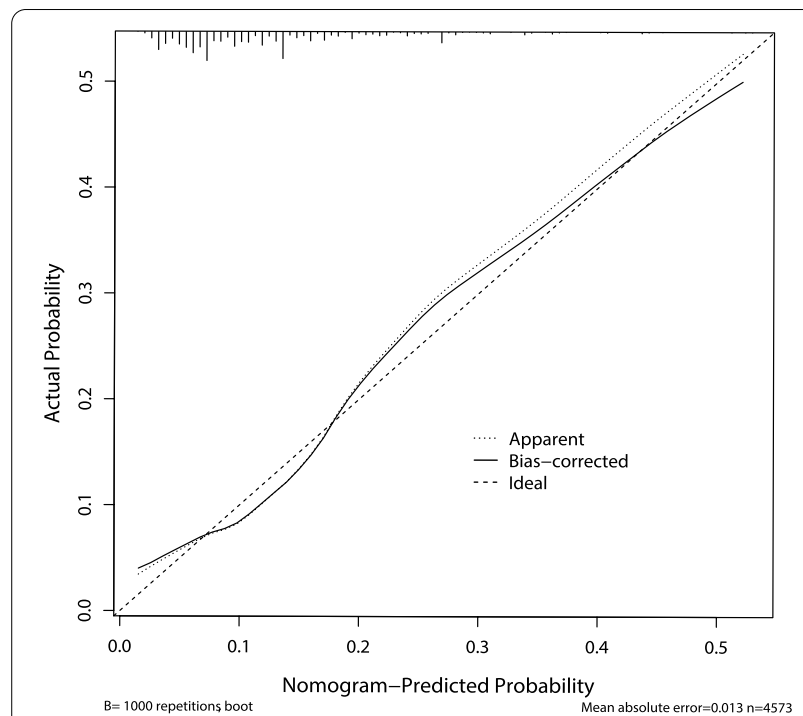

Fig. 3 The calibration curve of the nomogram model. For the calibration curve, the $X$-axis is the predicted probability, and the Y-axis is the actual probability. The diagonal (ideal curve/dashed line) meant the prediction probability was completely consistent with the actual rate, and our curve (apparent curve/solid line) was close to the diagonal, which suggested that this model shows good predictive performance

and funds. There is a shortage of dental professionals in China, and the number of children suffering from tooth decay is large. For this reason, these methods are not applicable for caries screening in large-scale populations.

In our study, a simple-to-use predictive model was conducted based on dental examinations and questionnaires from a cross-sectional survey in Sichuan Province. The cumulative points of every independent variable in the nomogram could be calculated and matched to the scale of risk possibility. We recommend a two-stage stratified screening for severe caries among 12-year-old children in Sichuan Province: (i) The proposed nomogram is used in the first stage to reduce manpower and financial resources. Non-dental professionals administer questionnaires involving six risk factors and calculate the risk value of severe caries according to the model. If a risk value is higher than 0.1332 (cut-off point), it is recommended to visit a dentist as early as possible and enter the second stage; if the value is below the cut-off point, regular oral examinations (two times per year) are recommended. (ii) In the second stage, CRA tools or other oral examinations are conducted by dental specialists to further assess the severity of caries.

Risk factors in our study were mainly associated with socio-demographic information and dental experiences. In accordance with previous studies [27, 28], "female children" have a higher risk factor for caries of permanent teeth. Their caries prevalence is associated with earlier tooth eruption [29], low salivary flow rate, sugar consumption [30] and dental phobia [31, 32], which may require improvements in dental education, medical environmental design, and doctor-patient communication.

Caries experience was the primary risk factor [33, 34]. The relationship between caries experience and dental visit information was corroborated by previous research $[35,36]$. It seems contradictory that children who visit the dentist more often have a higher likelihood of caries. A possible reason for this is that many parents take their children to the dentist only for treatment instead of prevention. A cariogenic oral environment formed by caries without treatment would exacerbate cavities, as has been previously reported [37]. Under these circumstances, it is recommended that parents regularly take their children to the hospital for dental examinations. Additionally, more oral health education, collaboration between parents and schools, and more local medical facilities are oral health strategies in Sichuan Province.

The subjective impression of oral health seems to have good predictive power [38]. A previous study showed significant differences in the "self-assessment of teeth" [28] among 12-year-old students. In the present study, "very poor oral health for self-assessment" was the most strongly weighted variable that contributed to the risk of severe caries. Region, urbanization, and only child were the other three independent predictors of severe caries, which is consistent with previous research [39-41].

An interesting finding was that lifestyle and behavioural factors such as a sugary diet, frequency of tooth brushing, and fluoride toothpaste and dental floss use, which were widely mentioned in dental epidemiological research [42-44], were not included. This difference may be explained differences between the outcome variable in our study (i.e., whether a child had severe caries $(\mathrm{DMFT} \geq 3))$ and the outcome variables used in previous research [45]. 
For model validation, we used two $\mathrm{CV}$ methods. In general, AUCs lower than 0.6 are considered to have poor discrimination, while AUCs higher than 0.7 suggest high discriminating ability. Both the fivefold and leave-oneout $\mathrm{CV}$ methods indicate a good discriminating ability of our nomogram for severe caries.

The strengths of this research are related to its large cross-sectional study design, in which the representative districts and counties of Sichuan Province were selected by a multistage sampling design. In addition, the results of the screening model are displayed with a simple and intuitive graphical form, which facilitates the children and their parents understanding and attracts their attention. However, if the sample size is expanded, the model based on national data will be more practical. Additionally, this model developed herein should be further validated via a longitudinal study.

\section{Conclusion}

Gender, region, urbanization, only child, self-assessment of oral status, and time of last dental visit were shown to be highly correlated with caries risk. The nomogram is a simple-to-use way to identify children who have severe caries (DMFT $\geq 3$ ) and was found to facilitate non-dental professionals in predicting risk values without oral examinations and making referrals to dental professionals.

\begin{abstract}
Abbreviations
DMFT: Decayed, missing or filled permanent teeth; WHO: World Health Organization; FDI: International dental federation; PPS: Probability proportional to size; CPI: Community Periodontal Index; OR: Odds ratio; Cl: Confidence intervals; CV: Cross-validation; FPR: False-positive rate; FNR: False-negative rate; NPV: Negative predictive value; PPV: Positive predictive value; YI: Youden Index; AUC: Area under curve; ROC: Receiver operating characteristic; CRA: Caries risk assessment.
\end{abstract}

\section{Supplementary Information}

The online version contains supplementary material available at https://doi. org/10.1186/s12903-021-01819-2.

Additional file 1. Overview of the questionnaire

\section{Acknowledgements}

A special thanks to Song J.Q., Hong X., Wang L.Y. and Chen H. for advice.

\section{Authors' contributions}

TH conceived and designed the experiments; JZ, HY and JH performed the experiments; $R C$ and ML analysed the data; SD and ML wrote the paper. $\mathrm{LL}$ gave suggestions about modification. All authors have read and approved the final manuscript.

\section{Funding}

This work was supported by a grant for the Key Research and Development Program of China of Sichuan Province (Grant No. 20ZDYF3012) and the 2015 Chinese Institute of Stomatology Public Welfare Industry Research Project (Grant No. 201502002). The funders had no role in the design of the study and the collection, analysis, and interpretation of data or in writing the manuscript.

\section{Availability of data and materials}

The dataset of the study is available from the corresponding author at reasonable request.

\section{Declarations}

Ethics approval and consent to participate

All procedures performed in the study were in accordance with the ethical standards of the institutional and/or national research committee (locally approved by the ethics committee of the Stomatological Ethics Committee of the Chinese Stomatological Association and the Ethics Committee of the West China Hospital of Stomatology, Sichuan University: 2014-003). After parents signed informed consent forms, examinations were conducted with mobile dental chairs and portable lights.

\section{Consent for publication}

Not applicable.

\section{Competing interests}

The authors declare that they have no conflict of interest.

\section{Author details}

${ }^{1}$ Department of Preventive Dentistry, State Key Laboratory of Oral Diseases, National Clinical Research Center for Oral Diseases, West China Hospital of Stomatology, Sichuan University, Chengdu, Sichuan, China. ${ }^{2}$ Orange Dental Technology Co., Ltd., Shanghai, China.

Received: 23 April 2021 Accepted: 10 September 2021

Published online: 20 September 2021

\section{References}

1. Kassebaum NJ, Bernabé E, Dahiya M, Bhandari B, Murray CJ, Marcenes W. Global burden of untreated caries: a systematic review and metaregression. J Dent Res. 2015;94(5):650-8.

2. Peres MA, Macpherson LMD, Weyant RJ, Daly B, Venturelli R, Mathur MR, Listl S, Celeste RK, Guarnizo-Herreño CC, Kearns C, et al. Oral diseases: a global public health challenge. Lancet. 2019;394(10194):249-60.

3. Krisdapong S, Prasertsom P, Rattanarangsima K, Sheiham A. Relationships between oral diseases and impacts on Thai schoolchildren's quality of life: evidence from a Thai national oral health survey of 12- and 15-year-olds. Commun Dent Oral Epidemiol. 2012;40(6):550-9.

4. Barmes DE. Indicators for oral health and their implications for developing countries. Int Dent J. 1983;33(1):60-6.

5. Hobdell M, Petersen PE, Clarkson J, Johnson N. Global goals for oral health 2020. Int Dent J. 2003;53(5):285-8.

6. Oral Health Country/Area Profile Project. https://capp.mau.se/countryareas/china/. Accessd 20 June 2021

7. Wei SH, Holm AK, Tong LS, Yuen SW. Dental caries prevalence and related factors in 5-year-old children in Hong Kong. Pediatr Dent. 1993;15(2):116-9.

8. Lo E, Chu C, Lin H. Caries control programme for children in China: one year results. J Dent Res. 2001;80(4):1377-1377.

9. Bratthall D. Introducing the Significant Caries Index together with a proposal for a new global oral health goal for 12-year-olds. Int Dent J. 2000;50(6):378-84.

10. Hosseinpoor AR, Itani L, Petersen PE. Socio-economic inequality in oral healthcare coverage: results from the World Health Survey. J Dent Res. 2012;91(3):275-81.

11. Commission NHAF: The Chinese Health Statistics Yearbook Peking Union Medical College Press; 2019.

12. Lei Z, Li J, Wu D, Xia Y, Wang Q, Si A, Wang K, Wan X, Lau WY, Wu M, et al. Nomogram for preoperative estimation of microvascular invasion risk in hepatitis B virus-related hepatocellular carcinoma within the Milan criteria. JAMA Surg. 2016;151(4):356-63.

13. Xue M, Su Y, Feng Z, Wang S, Zhang M, Wang K, Yao H. A nomogram model for screening the risk of diabetes in a large-scale Chinese 
population: an observational study from 345,718 participants. Sci Rep 2020;10(1):11600.

14. Mo R, Shi R, Hu Y, Hu F. Nomogram-based prediction of the risk of diabetic retinopathy: a retrospective study. J Diabetes Res. 2020;2020:7261047.

15. Schwahn C, Meisel P, Biffar R, König J, John U, Kocher T. Dental nomograms for benchmarking based on the study of health in Pomerania data set. J Clin Periodontol. 2004;31(12):1099-105.

16. Lu HX, Tao DY, Lo ECM, Li R, Wang X, Tai BJ, Hu Y, Lin HC, Wang B, Si Y, et al. The 4th national oral health survey in the mainland of China: background and methodology. Chin J Dent Res. 2018;21(3):161-5.

17. Lohr SL. Sampling: design and analysis. Boca Raton: CRC Press; 2019.

18. Yin W, Yang Y-M, Chen H, Li X, Wang Z, Cheng L, Yin Q-D, Fang H-Z, Fei W, Mi F-L, et al. Oral health status in Sichuan Province: findings from the oral health survey of Sichuan, 2015-2016. Int J Oral Sci. 2017;9(1):10-5.

19. Wu SC, Ma XX, Zhang ZY, Lo ECM, Wang X, Wang B, Tai BJ, Hu DY, Lin HC, Wang $C X$, et al. Ethnic disparities in dental caries among adolescents in China. J Dent Res. 2021;100(5):496-506.

20. Organization WHO: Oral health surveys: basic methods: World Health Organization. In: 5th edn; 2013.

21. Dawood S, Broglio K, Buzdar AU, Hortobagyi GN, Giordano SH. Prognosis of women with metastatic breast cancer by HER2 status and trastuzumab treatment: an institutional-based review. J Clin Oncol. 2010;28(1):92-8.

22. Li J, Chen B, Gao C, Huang J, Wang Y, Zhang S, Xu Y, Guo W, Wang R. Clinical and pathological features of idiopathic membranous nephropathy with focal segmental sclerosis. BMC Nephrol. 2019;20(1):467-467.

23. Marthaler TM. Changes in dental caries 1953-2003. Caries Res. 2004;38(3):173-81.

24. Burt BA. Prevention policies in the light of the changed distribution of dental caries. Acta Odontol Scand. 1998;56(3):179-86.

25. Gaudilliere D, Thakur Y, Ku M, Kaur A, Shrestha P, Girod SC. Caries management by risk assessment in a cleft and craniofacial center. J Craniofac Surg. 2014;25(6):e529-536.

26. Young DA, Featherstone JD. Caries management by risk assessment. Commun Dent Oral Epidemiol. 2013;41(1):e53-63.

27. Chu CH, Wang JH, Jan RH, Huang $\mathrm{CH}$, Cheng CF. Association between health examination items and body mass index among school children in Hualien, Taiwan. BMC Public Health. 2013;13:975.

28. Chen C, Zhang F, Wang R. Dental caries experience and related risk indicators of 12-year-old students in Jilin, China. Med Baltim. 2020;99(28):20988.

29. Martinez-Mier EA, Zandona AF. The impact of gender on caries prevalence and risk assessment. Dent Clin North Am. 2013:57(2):301-15.

30. Kunitomo M, Ekuni D, Mizutani S, Tomofuji T, Irie K, Azuma T, Yamane M, Kataoka K, Taniguchi-Tabata A, Mizuno H, et al. Association between knowledge about comprehensive food education and increase in dental caries in Japanese University Students: a prospective cohort study. Nutrients. 2016;8(3):114.
31. Oosterink FM, de Jongh A, Hoogstraten J. Prevalence of dental fear and phobia relative to other fear and phobia subtypes. Eur J Oral Sci. 2009;117(2):135-43.

32. Wabnegger A, Scharmüller W, Schienle A. Sex-specific associations between grey matter volume and phobic symptoms in dental phobia. Neurosci Lett. 2014;580:83-7.

33. Zhang $\mathrm{Q}$, van Palenstein Helderman WH. Caries experience variables as indicators in caries risk assessment in 6-7-year-old Chinese children. J Dent. 2006:34(9):676-81.

34. Birkeland JM, Broach L, Jorkjend L. Caries experience as predictor for caries incidence. Commun Dent Oral Epidemiol. 1976;4(2):66-9.

35. Christian B, Ummer-Christian R, Blinkhorn A, Hegde V, Nandakumar K, Marino R, Chattopadhyay A. An epidemiological study of dental caries and associated factors among children residing in orphanages in Kerala, India: Health in Orphanages Project (HOPe). Int Dent J. 2019;69(2):113-8.

36. Zhou N, Wong HM, McGrath C. Oral health and associated factors among preschool children with special healthcare needs. Oral Dis. 2019:25(4):1221-8.

37. Mak KK, Day JR. Dental health behaviours among early adolescents in Hong Kong. Int J Dent Hyg. 2011:9(2):122-6.

38. Zandona AF, Longbottom C. Detection and assessment of dental caries: a clinical guide. Basingstoke: Springer Nature; 2019.

39. David J, Wang NJ, Astrøm AN, Kuriakose S. Dental caries and associated factors in 12-year-old schoolchildren in Thiruvananthapuram, Kerala, India. Int J Paediatr Dent. 2005;15(6):420-8.

40. Tsai Al, Chen CY, Li LA, Hsiang CL, Hsu KH. Risk indicators for early childhood caries in Taiwan. Commun Dent Oral Epidemiol. 2006;34(6):437-45.

41. Odom JG, Mourino AP, Gordon MA, Odom SS. The only child: candidate for increased dental care. Pediatr Dent. 1983;5(1):72-4.

42. Walsh T, Worthington HV, Glenny AM, Marinho VC, Jeroncic A. Fluoride toothpastes of different concentrations for preventing dental caries. Cochrane Database Syst Rev. 2019;3(3):Cd007868.

43. Giacaman RA. Sugars and beyond: the role of sugars and the other nutrients and their potential impact on caries. Oral Dis. 2018;24(7):1185-97.

44. Touger-Decker R, Van Loveren C. Sugars and dental caries. Am J Clin Nutr. 2003;78(4):881S-892S

45. Kyaw Myint ZC, Zaitsu T, Oshiro A, Ueno M, Soe KK, Kawaguchi Y. Risk indicators of dental caries and gingivitis among 10-11-year-old students in Yangon, Myanmar. Int Dent J. 2020;70(3):167-75.

\section{Publisher's Note}

Springer Nature remains neutral with regard to jurisdictional claims in published maps and institutional affiliations.
Ready to submit your research? Choose BMC and benefit from:

- fast, convenient online submission

- thorough peer review by experienced researchers in your field

- rapid publication on acceptance

- support for research data, including large and complex data types

- gold Open Access which fosters wider collaboration and increased citations

- maximum visibility for your research: over $100 \mathrm{M}$ website views per year

At $\mathrm{BMC}$, research is always in progress.

Learn more biomedcentral.com/submissions 